\title{
X-linked recessive inheritance of radial ray deficiencies in a family with four affected males
}

\author{
Robert-Jan H Galjaard ${ }^{\star}, 1$, Naci Kostakoglu ${ }^{4}$, Jeannette JM Hoogeboom ${ }^{1}$, Guido J Breedveld ${ }^{1}$ \\ Herma C van der Linde ${ }^{1}$, Steven ER Hovius ${ }^{2}$, Ben A Oostra ${ }^{1}$, Lodewijk A Sandkuijl ${ }^{1}$, \\ A Nurten Akarsu ${ }^{3}$ and Peter Heutink ${ }^{1}$

\begin{abstract}
${ }^{1}$ Department of Clinical Genetics, Erasmus University/University Hospital, Rotterdam, The Netherlands; ${ }^{2}$ Department of Plastic and Reconstructive Surgery, University Hospital Rotterdam, The Netherlands; ${ }^{3}$ Gene Mapping Laboratory, Basic and Applied Research Center of the Department of Pediatrics, Hacettepe University, Ankara, Turkey; ${ }^{4}$ Department of Plastic and Reconstructive Surgery, Hacettepe University, Ankara, Turkey
\end{abstract}

Radial ray deficiencies are frequently associated with additional clinical anomalies and have a heterogeneous aetiology. X-linked forms are extremely rare. We report a family in which four male relatives show bilateral absence of the radius with presence of the thumbs and associated anomalies. The segregation of the phenotype is suggestive for $\mathrm{X}$-linked recessive inheritance. This is confirmed by performing linkage analysis using 24 markers spanning the $X$ chromosome in which a maximum lod score of 1.93 for DXS8067 and DXS1001 is obtained. We defined a critical region of maximal $16.2 \mathrm{cM}$ on the $\mathrm{X}$ chromosome with haplotype analysis. European Journal of Human Genetics (2001) 9, 653-658.

Keywords: radial ray deficiency; X-linked recessive; linkage mapping

\section{Introduction}

Radial ray deficiencies have an incidence of about $1: 10000$ live births. ${ }^{1}$ They occur either isolated or associated with additional clinical anomalies. ${ }^{1,2}$ Radial ray deficiencies are clinically and genetically very heterogeneous. Many cases are sporadic and considered to be multifactorial in origin. Although radial ray deficiencies are more commonly present in males than in females, ${ }^{1} \mathrm{X}$-linked inheritance has only been described for a few cases. Four families with possibly $\mathrm{X}$ linked VACTERL-H (OMIM 314390) have been published. ${ }^{3,4}$ Furthermore, a phenotype of radial aplasia and associated anomalies in a male and his maternal uncle (OMIM 312190), suggestive of $\mathrm{X}$-linked recessive inheritance has been described. $^{5}$

We present a family in which four male relatives have total absence of the radii, presence of the thumbs, and several

*Correspondence: R-J H Galjaard, Department of Clinical Genetics, Erasmus University Rotterdam, P.O. Box 1738, 3000 DR Rotterdam, The Netherlands. Tel: +31 10 4087214; Fax: +31 10 4087200;

E-mail: r.j.h.galjaard@kgen.fgg.eur.nl

Received 2 March 2001; revised 22 May 2001; accepted 30 May 2001 variable associated anomalies. Since all affected individuals are male, and no male to male transmission was observed, an $\mathrm{X}$-linked recessive mode of inheritance was assumed. We tested 24 microsatellite markers on the $\mathrm{X}$ chromosome, performed linkage analysis, and constructed haplotypes. The results of these studies indicate that the phenotype of our patients is linked to Xq24-25.

\section{Subjects and methods}

Patients

There are no consanguineous marriages in this family of Turkish origin. Physical examination of the index patient (III-5, Figure 1) and his parents was done several times in the Netherlands. Patient KM (III-1, Figure 1) and his parents, patient AS and one of his unaffected brothers (II6 and II-5, Figure 1), were examined in Turkey. Information of the remaining family members was obtained by family history. Photographs were examined of the unaffected sib(s) of patients OS and KM (III-1,2,4, Figure 1) and the other unaffected brother of patient AS (II-7, Figure 1). 


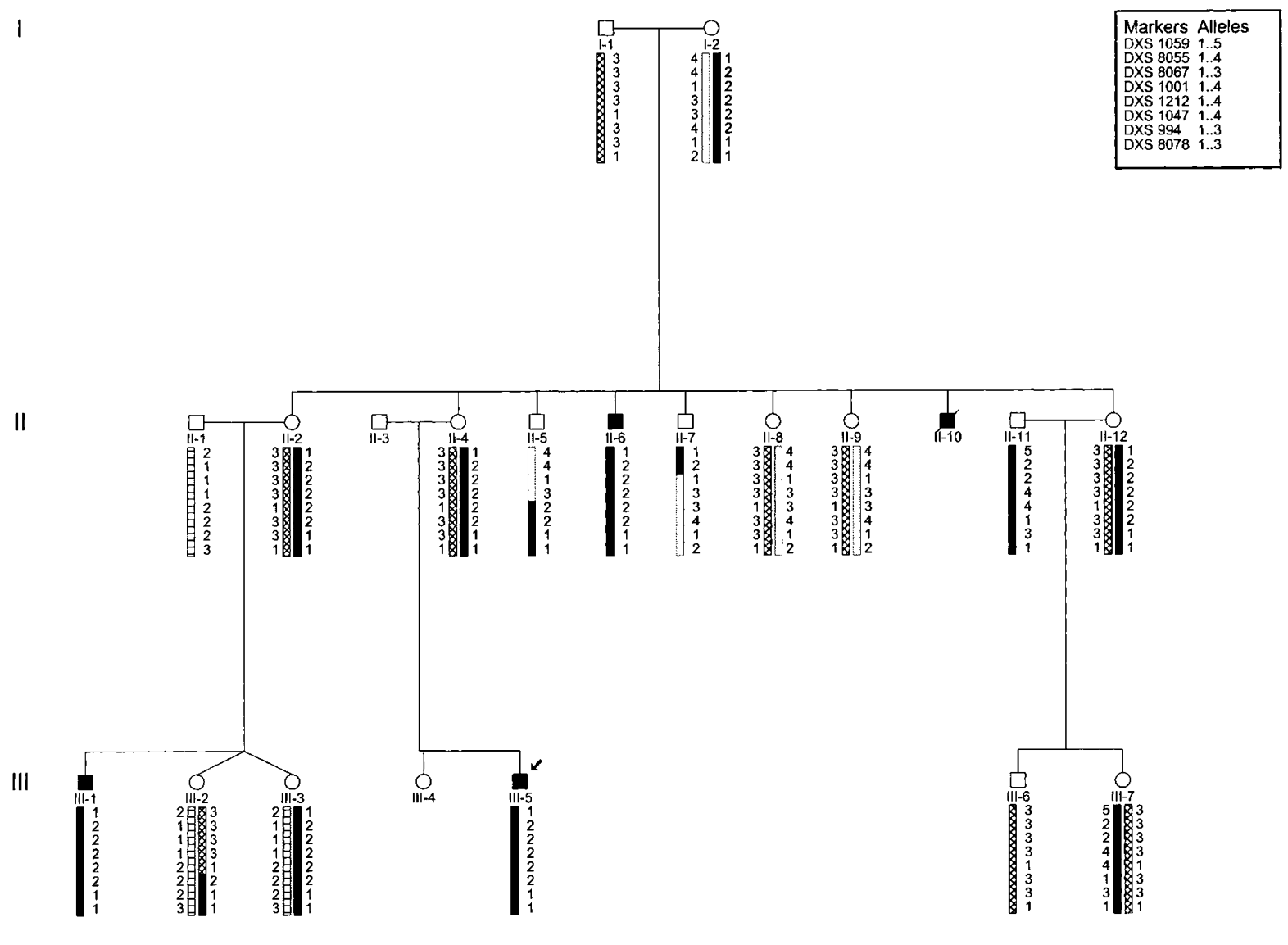

Figure 1 Pedigree diagram of the family. The markers shown are restricted to those between DXS1059 and DXS8078. Distances between markers in CM: DXS1059-2.71-DXS8055-4.9-DXS8067-0-DXS1001-0-DXS1212-6.26-DXS1047-0.77-DXS994-0-DXS8078. The three patients (II-6, III-1, III-5 pedigree diagram) share an identical haplotype telomeric from DXS990. Two unaffected males (II-5, II-7 pedigree diagram) have also part of this haplotype except for the region between DXS8055 and DXS1212.

\section{Cytogenetic studies}

GTG -banded metaphases from blood lymphocytes were used for karyotyping the index patient. Skin fibroblasts were tested for chromosome breakage after exposure to diepoxybutane (DEB).

\section{Molecular studies}

Blood was obtained from 18 family members after informed consent and genomic DNA was isolated as described before. ${ }^{6}$ We tested 24 microsatellite markers; 20 from Généthon, ${ }^{7}$ DXS451 and DXS538 from Reed et al, ${ }^{8}$ and DXS7132 and DXS6800 from the integrated genetic map provided by the Center of Medical Genetics, Marshfield, USA (htpp:// www.marshmed.org). We choose this map because the distances between most markers, except DXS451, are well defined. For DXS451 the relative position was estimated according to published data. ${ }^{8}$ Analysis of polymorphic markers was performed essentially as described before. ${ }^{9}$ PCR conditions were : $10 \mathrm{~min}$ denaturation at $94^{\circ} \mathrm{C}$ followed by 25 cycles of $94^{\circ} \mathrm{C}$ for $30 \mathrm{~s}, 55^{\circ} \mathrm{C}$ for $30 \mathrm{~s}, 72^{\circ} \mathrm{C}$ for $90 \mathrm{~s}$, with a final extension at $72^{\circ} \mathrm{C}$ for $5 \mathrm{~min}$. PCR products were separated on denaturing polyacrylamide gels. Alleles were visualised by autoradiograpy.

\section{Mutation analysis}

Three sets of primers (available upon request) were designed from genomic sequence obtained from Genbank (Accession no X98253) to amplify the coding region and intron-exon boundaries of the ZNF 183 gene. PCR products from genomic DNA of all the patients and normal (family) members were sequenced on an automated sequencer (Perkin Elmer's ABI Prism 377 DNA sequencer, Foster City, USA) using big dye chemistry. For the IAP 3 gene mRNA sequence was obtained from Genbank (U45880) to design eight sets of primers (available upon request) for amplification and sequencing of cDNA according to standard procedures.

\section{Linkage data}

Two point linkage analysis using the LINKAGE program, version $5.01,{ }^{10}$ was performed on all markers tested except for 
DXS451, and DXS538, DXS1068, DXS7132, DXS8064 which were not informative in this family. X-linked recessive inheritance of radial anomalies was assumed with full penetrance in males, no anomalies in female carriers, and a gene frequency of $1: 1000$. Multipoint linkage analysis was performed by subsequent four-point analyses on these markers.

\section{Results}

Patients

The abnormalities noticed in the four patients are summarised in Table 1. The index patient OS (III-5, Figure 1) was born after an uncomplicated pregnancy and delivery. At birth his weight was $3200 \mathrm{~g}$ (10th centile), his length $50 \mathrm{~cm}$ (50th centile) and his head circumference (HC) $35 \mathrm{~cm}$ (50th centile). The following congenital malformations were noticed: Upper extremities: bilateral short curved forearms, radial deviation with an extension deficit of $90^{\circ}$ of the wrists, and short thumbs. Lower extremities: genu varum of the right leg and slight subluxation of the right knee. Radiographs of the upper extremities showed absence of the radii, broad curved ulnae and hypoplasia of the thumbs. Radiographs of the skeleton except for the extremities showed no abnormalities. A Dandy-Walker malformation was seen on a CT-scan. Transposition of the great arteries (TGA), and an atrial septal defect (ASD) type 2 were seen on ultrasound. Ultrasound examination of the abdomen showed no abnormalities. Thrombocytopenia was excluded repeatedly, also during the first year of life. Other hematological disorders were also excluded on routine hematologic laboratory tests. At the age of 2 years and 7 months his mental development was normal. His weight was $11 \mathrm{~kg}$ (3rd centile), his length was $86 \mathrm{~cm}$ (10th centile), and his HC was $47 \mathrm{~cm}$ (3rd centile). His left arm and legs are shown in Figure 2 .

Patient KM (III-1, Figure 1) is a 7-year-old male with short stature. He has the same anomalies of the upper extremities

Table 1 Summary of anomalies in patients of present paper

\begin{tabular}{lccccc}
\hline Anomalies & OS & KM & AS & 4th Pat & Total \\
\hline Short stature & - & + & + & $?$ & $2 / 3$ \\
Absent radii & + & + & + & + & $4 / 4$ \\
Hypoplastic thumbs & + & + & - & $?$ & $2 / 3$ \\
Hypoplastic fingers & - & - & + & $?$ & $1 / 3$ \\
Contracture fingers & + & + & + & $?$ & $3 / 3$ \\
Hypoplastic toes & - & - & + & $?$ & $1 / 3$ \\
Genu varum knee & + & - & + & $?$ & $2 / 3$ \\
Contractures knees & - & + & - & $?$ & $1 / 3$ \\
Absent patellae & - & + & - & $?$ & $1 / 3$ \\
Cardiac anomaly & + & - & + & $?$ & $2 / 3$ \\
Dandy-Walker malf. & + & - & - & $?$ & $1 / 3$ \\
\hline + indicates presence; & - indicates absence of anomaly; ? indicates \\
not known. & & \multicolumn{7}{r}{}
\end{tabular}

as OS and an extension deficit of the 2nd to 4th metacarpophalangeal joints of boths hands (Figure 2). His lower extremities show abducted hip joints, postnatally developed contractures of both knees with popliteal pterygiae (Figure 2), and bilateral absence of the patellae (Table 1). There is no history of a bleeding disorder. Standard laboratory tests showed normal results. Cardiac evaluation did not reveal an abnormality.

Patient AS (II-6, Figure 1) is a 28-year-old male with short stature. He shares the anomalies of the upper extremities with OS. In addition he has hypoplastic middle and distal phalanges of the 2 nd to 4 th fingers of his left hand. The middle and distal phalanges of the index finger of his right hand are also hypoplastic. All his fingers show an extension deficit. He has genu varum of the right leg, but he has also hypoplasia of the 3rd to 5th toes and the 4th and 5th toes of his left and right foot, respectively. In the past thrombocytopenia was excluded. Cardiac ultrasound revealed a 3rd degree aortic stenosis attributed to rheumatic fever in the
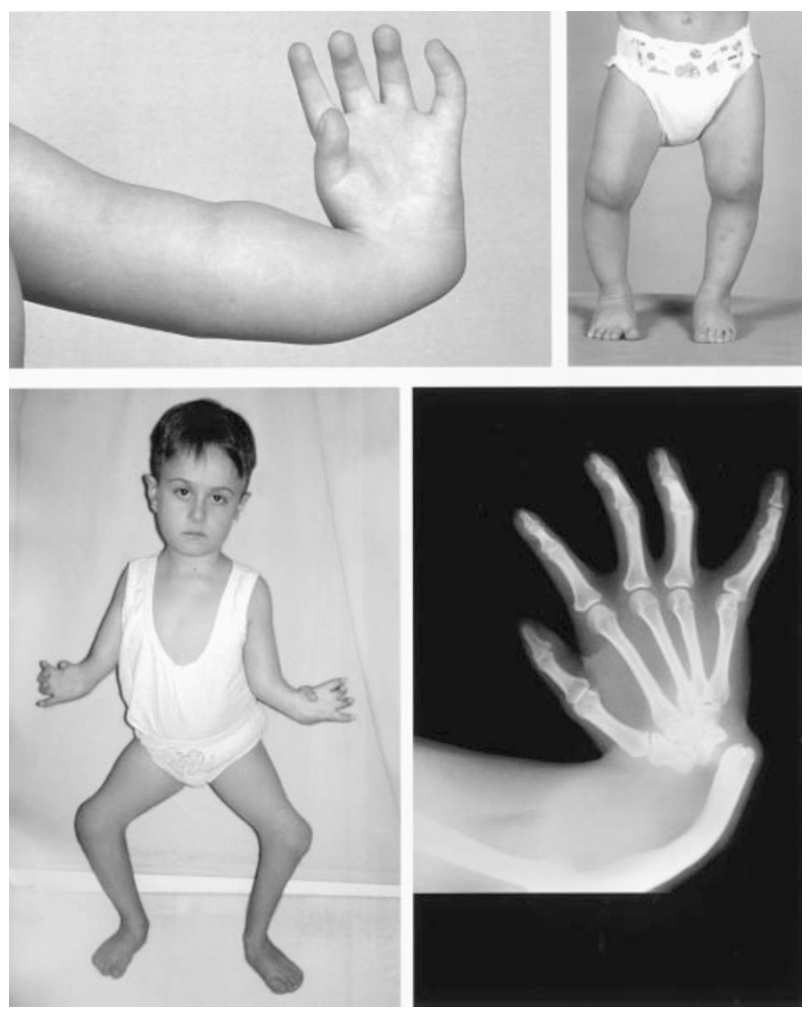

Figure 2 Extremities of the patients OS and KM (III-1, III-5 pedigree diagram, resp.). Left upper photo: Short curved left forearm with radial deviation and an extension deficit of the wrist, and hypoplastic thumb of patient OS. Right upper photo: Genu varum of the right leg of patient OS. Left lower photo: Bilateral short curved forearms, extension deficit of the elbows and 2nd to 4th MCP joints of the hands, hypoplastic thumbs, abducted hip joints, and contractures of the knees with pterigiae poplitiae of patient KM. Right lower photo: Absent radius, short curved ulna and hypoplastic thumb. 
past. Ultrasound of the abdomen did not show anomalies. The fourth patient (II-10, Figure 1) had bilateral short curved forearms with an extension deficit of his wrists. He did not have associated anomalies. He died of an infectious disease about 2-3 months after birth. All the other relatives of the male patients are healthy. A radiograph of the forearm of the mother of our index patient did not show an abnormality.

\section{Cytogenetic studies}

The index patient has a normal male karyotype. No spontaneous or induced breakage of chromosomes was noticed after DEB exposure.

\section{Molecular studies}

Twenty-four markers spanning the X chromosome at regular intervals were tested. With two point linkage analysis a maximum lod score of 1.93 for DXS8067 and DXS1001 at zero recombination frequency was obtained. This result is confirmed by multipoint analysis (Figure 3).

Haplotypes were constructed for the entire chromosome. The patients share an identical haplotype from DXS990 to DXS1193. A double recombinant would be present for individual II-5 in case DXS1212 is positioned centromeric of DXS1001 as indicated by the Marshfield data. Our data indicate that DXS1212 is located telomeric of DXS1001. This is in accordance with data from Généthon and Nagaraja et al. ${ }^{7,11}$ Therefore, we choose the order DXS8067, DXS1001, and DXS1212 (Figure 1). The unaffected males II-5, and II-7 share part of the haplotype of the patients except for the region between DXS8055 and DXS1212 (Figure 1). The results of the linkage and haplotype analysis show the responsible gene defect must be localised between these two markers. According to the genetic map of the $\mathrm{X}$ chromosome of Marshfield, this interval is about $4.9 \mathrm{cM}$. According the genetic map of Généthon and that of Nagaraja et al, ${ }^{7,11}$ this interval is about $16.2 \mathrm{cM}$. We performed mutation analysis for two candidate genes in this interval; the ZNF183 and IAP 3 genes and did not find a disease causing mutation in these genes.

\section{Discussion}

We report a family with a radial ray deficiency, presence of thumbs and associated anomalies. In our view, our patients have a previously unreported phenotype. Our differential diagnosis included autosomal recessive TAR syndrome, Fanconi anaemia (FA), X-linked recessive VACTERL-H syndrome, and a phenotype described by Gibson et al. ${ }^{5}$ TAR syndrome can be rejected when thrombocytopenia is excluded. ${ }^{12}$ FA is an unlikely diagnosis in the absence of

\section{multipoint analysis}

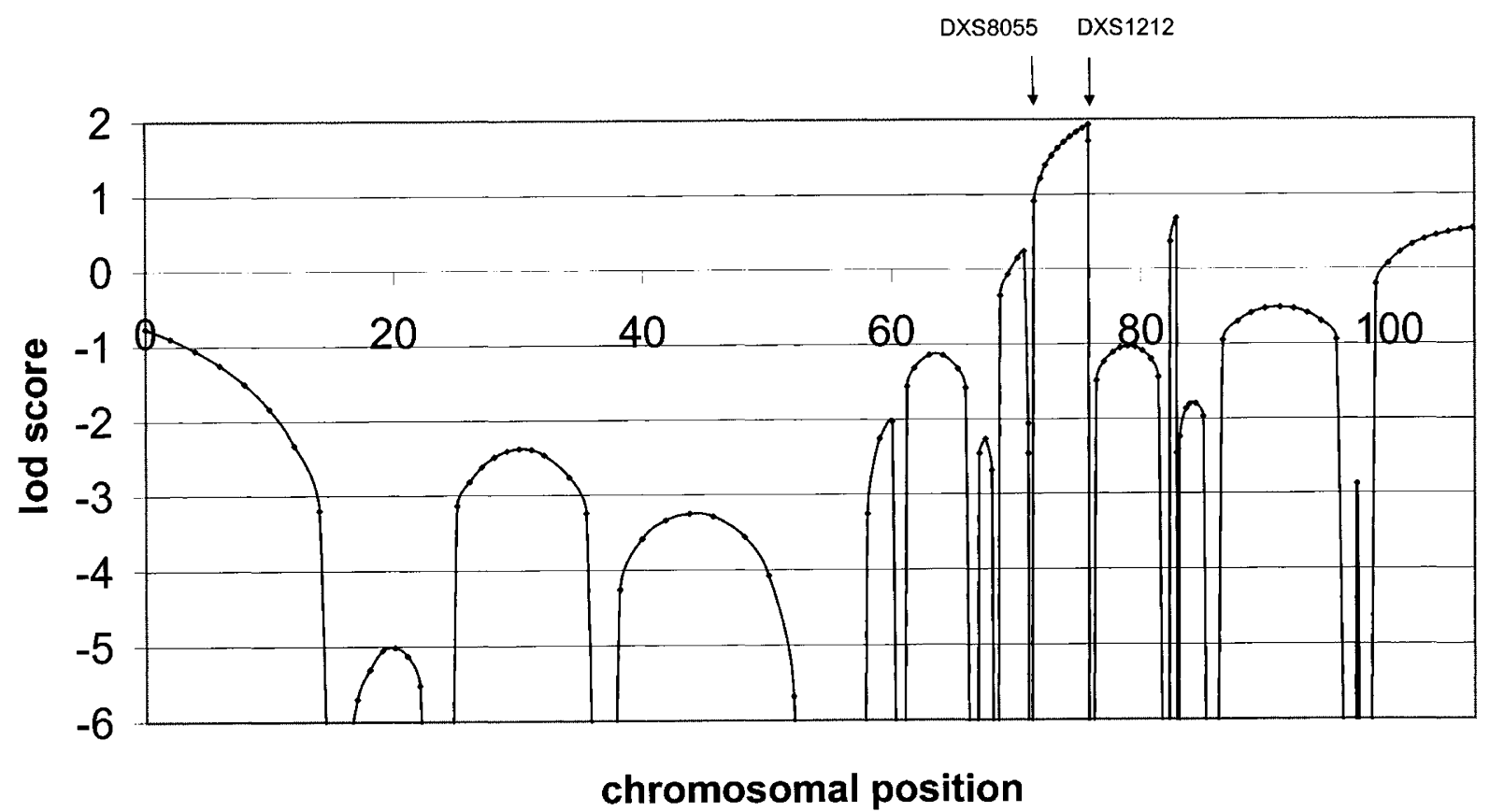

Figure 3 Multipoint lodscores for twenty tested X-chromosomal markers. X-axis: the distance in cM. The most telomeric marker tested DXS996 was used as a point of reference (0), and the one on the right is DXS1193. The highest lodscores are obtained in the region in between DXS8055 and DXS1212. 
chromosome breakage after DEB exposure. ${ }^{13}$ There are 12 cases published with X-linked VACTERL-H; 10 cases summarised by Lomas et al., ${ }^{3}$ and two cases by Froster et $a l .{ }^{4}$ In Table 2 we summarise these cases, the two cases with $\mathrm{X}$-linked radial aplasia, ${ }^{5}$ and the cases presented in this study. Our index patient has been evaluated for all defects summarised by Lomas et al. ${ }^{3}$ He shares only radial aplasia and a cardiac anomaly with the cases described with $\mathrm{X}$ linked VACTERL-H cases. Moreover, his life expectancy is different from that in these patients. The cases described by Gibson et al., ${ }^{5}$ only share radial aplasia with our patients. Therefore, we do not think our patients have the same phenotype.

The phenotype of our patients can be caused by a defect of a single gene or several closely linked genes. Alternatively, large variability in the phenotype might be caused by either modifier genes located elsewhere on the genome or environmental factors. A literature search for patients with a radial ray deficiency and a chromosomal anomaly involving our defined critical region revealed no cases, which limits the search for a gene causing the phenotype to a candidate gene approach. Since absence of the radii is the most consistently present anomaly in our patients we hypothesise that the responsible gene must be involved in patterning, differentiation, or apoptosis during human embryonic limb development. In our patients the gene defect could have its major effect on the mesenchymal condensation process of the anterior (radial) part of the upper limb, comparable with the effects of the mutant TBX5 gene. $^{14,15}$ Haploinsufficiency of this gene causes mainly anterior limb malformations in patients with Holt-Oram syndrome, whereas haploinsufficiency of the TBX3 gene causes mainly posterior limb malformations in patients with the ulnar-mammary syndrome. ${ }^{14,16}$

Table 2 Summary of anomalies in cases with VACTERL-H and $\mathrm{X}$-linked radial aplasia

\begin{tabular}{lllllll}
\hline Anomalies & $1^{a}$ & $2^{b}$ & $3^{c}$ & $4^{d}$ & $5^{e}$ & $6^{f}$ \\
\hline Hydrocephalus & $4 / 4$ & $2 / 2$ & $4 / 4$ & $2 / 2$ & $1 / 1$ & $0 / 3$ \\
Radial anomalies & $4 / 4$ & $2 / 2$ & $4 / 4$ & $2 / 2$ & $2 / 2$ & $4 / 4$ \\
Anal atresia & $2 / 2$ & $2 / 2$ & $3 / 4$ & $1 / 2$ & $1 / 2$ & $0 / 4$ \\
Genital anomalies & $2 / 2$ & $1 / 1$ & $2 / 3$ & $?$ & $1 / 2$ & $0 / 4$ \\
Renal anomalies & $2 / 2$ & $2 / 2$ & $2 / 2$ & $1 / 2$ & $?$ & $0 / 2$ \\
T.E.F./Atresia & $1 / 1$ & $1 / 2$ & $1 / 3$ & $1 / 2$ & $?$ & $0 / 1$ \\
Vertebral anomalies & $1 / 1$ & $?$ & $0 / 1$ & $1 / 2$ & $?$ & $0 / 1$ \\
Cardiac anomalies & $?$ & $?$ & $1 / 3$ & $1 / 2$ & $?$ & $2 / 2$ \\
Lung anomalies & $?$ & $?$ & $0 / 3$ & $1 / 2$ & $?$ & $0 / 1$ \\
Gut anomalies & $1 / 1$ & $1 / 1$ & $0 / 3$ & $1 / 2$ & $?$ & $?$ \\
Accessory spleens & $1 / 1$ & $0 / 1$ & $0 / 3$ & $?$ & $?$ & $0 / 2$ \\
Microphthalmia & $1 / 1$ & $0 / 1$ & $0 / 3$ & $2 / 2$ & $?$ & $0 / 3$ \\
Cleft palate & $1 / 1$ & $2 / 2$ & $0 / 3$ & $1 / 2$ & $?$ & $0 / 4$ \\
Ear anomalies & $2 / 2$ & $?$ & $0 / 3$ & $2 / 2$ & $?$ & $0 / 4$ \\
Died & $4 / 4$ & $2 / 2$ & $4 / 4$ & $2 / 2$ & $?$ & $1 / 4$ \\
\hline Authors: & &
\end{tabular}

Authors: $1^{\mathrm{a}}$, Lomas et al. $^{3}$ : family 1 , four cases; $2^{\mathrm{b}}$, family 2 cases; $3^{\mathrm{c}}$, family 3 , four cases; $4^{\mathrm{d}}$, Froster et al. ${ }^{4}$ : two cases; $5^{\mathrm{e}}$, Gibson et al. ${ }^{5}$ : two cases; $6^{\mathrm{f}}$, present paper: four cases. Anomalies indicated when known; ? means not known in any case of the family.
The gene defect could also be involved in differentiation or growth of the radius. Disturbance of the chondrofication process could result in a fibrous radius; ${ }^{17,18}$ disturbance of the ossification process in a cartilagenous one. ${ }^{19}$ Alternatively, the gene defect could also be involved in disturbance of apoptotic cell death eliminating mesenchymal cells which would normally be the precursors of the radius resulting in the absence of the radius. It has been suggested that the radius and the ulna are derived from one mesenchymal condensation separated by apoptotic cell death in the opaque patch. ${ }^{20,21}$ Considering the pathogenic mechanisms described above we searched for a likely candidate gene or transcript in our critical region with a possible function in pattern formation, cell differentiation, or apoptosis. Genes coding for zinc finger ( $\mathrm{ZF}$ ) containing proteins are known to be often involved in pattern formation. We searched the OMIM database and found the RING finger containing IAP (Inhibitor of apoptosis protein) 3 gene to be a likely candidate. IAP 3 is mapped to Xq25 by in situ hybridisation. ${ }^{22}$ It is expressed in all fetal and adult tissues except peripheral blood leucocytes. ${ }^{23}$

We also searched the Human Gene Map (http:// www.ncbi.nlm.nih.gov/genemap) and found the ZNF183 gene of the RING finger gene family. This gene is ubiquitously expressed and its function is unknown. ${ }^{24}$ We did not find a mutation in these genes in our patients. We are currently searching for additional families as an approach to identify the responsible gene, which could be a starting point for functional studies in order to obtain better insight in the pathogenesis of the disorder.

\section{Acknowledgments}

We thank the family for their cooperation. R Koppenol and $T$ de Vries Lentsch are acknowledged for their work on the illustrations. We thank Prof Dr H Galjaard and the foundation of Clinical Genetics Rotterdam for their support.

\section{References}

1 Froster UG, Baird PA: Upper limb deficiencies and associated malformations: a population-based study. Am J Med Genet 1992; 44: $767-781$.

2 Tentamy SA, McKusick VA: Radial defects; in The genetics of hand malformations. Alan R Liss, Inc., for the National Foundation-March of Dimes, New York, BD:OAS 1978, 14: $44-48$.

3 Lomas FE, Dahlstrom JE, Ford JH: VACTERL with hydrocephalus: family with X-linked VACTERL-H. Am J Med Genet 1998; 76: $74-78$.

4 Froster UG, Wallner SJ, Reusche E, Schwinger E, Rehder H: VACTERL with hydrocephalus and branchial arch defects: prenatal, clinical, and autopsy findings in two brothers. $\mathrm{Am} \mathrm{J}$ Med Genet 1996; 62: 169-172.

5 Gibson CC, Genest DR, Bieber FR, Holmes LB: X-linked phenotype of absent radius and anogenital anomalies. Am J Med Genet 1993; 45: $743-744$.

6 Miller SA, Dykes DD, Polesky HF: A simple salting out procedure for extracting DNA from human nucleated cells. Nucleic Acids Res 1988; 16: 1215 . 
7 Dib C, Fauré S, Fizames $C$ et al: The Généthon human genetic linkage map. Nature 1996; 380: A124-129.

8 Reed PW, Davies JL, Copeman JB et al: Chromosome-specific microsatellite sets for fluorescence-based, semi-automated genome mapping. Nat Genet 1994; 7: 390-395.

9 Weber JL, May PE: Abudant class of human DNA polymorphisms which can be typed using polymerase chain reaction. Am J Hum Genet 1989; 44: $388-396$.

10 Lathrop GM, Lalouel JM: Easy calculations of lodscores and genetic risks on a small computer. Am J Hum Genet 1984; 36: $460-465$.

11 Nagaraja R, McMillan S, Kere J et al: X chromosome map at 75-kb STS resolution, revealing extremes of recombination and GC content. Gen Res 1997; 7: 210-222.

12 Hall J. Thrombocytopenia and absent radius (TAR) syndrome. $J$ Med Genet 1987; 24: 79-83.

13 Giampietro PH, Adler-Brecher B, Verlander PC, Pavlakis SG, Davis JG, Auerbach AD: The need for more accurate and timely diagnosis in Fanconi anemia: a report from the International Fanconi Anemia Registry. Pediatrics 1993; 91 no 6: 1116-1120.

14 Yi Li Q, Newbury-Ecob RA, Terrett JA et al: Holt-Oram syndrome is caused by mutations in TBX5, a member of the Brachyury (T) gene family. Nat Genet 1997; 15: $21-29$.

15 Basson CT, Bachinsky DR, Lin RC et al: Mutations in human limb and cardiac malformation in Holt-Oram syndrome. Nat Genet 1997; 15: 30-35.

16 Bamshad M, Lin R, Law DJ, et al: Mutations in human TBX3 alter limb, apocrine and genital development in ulnar-mammary syndrome. Nat Genet 1997; 16: 311-315.
17 Heikel HVA: Aplasia and hypoplasia of the radius. Acta Orthop Scand Suppl 1959; 39: 9-150.

18 Flatt AE: Radial clubhand; in The care of congenital hand anomalies. Quality Medical Publishing Inc, St. Louis, Missouri 1994, 2nd ed, pp 366-341.

19 Duncan GJ, Omer GE, Garcia JF, Latimer E: Magnetic resonance imaging to visualize the internal anatomy in the Baller-Gerold syndrome. J Hand Surg 1993; 18A: 588-592.

20 Hinchliffe JR, Ede DA: Limb development in the polydactylous talpid3 mutant of the fowl. J Embryol Exp Morp 1967; 17: 385 404.

21 Dawd DS, Hinchliffe JR: Cell death in the "opaque patch" in the central mesenchyme of the developing chick limb: a cytological, cytochemical and electron microscopic analysis. J Embryol Exp Morp 1971; 3: 401-424.

22 Rajcan-Separovic E, Liston P, Lefebvre C, Korneluk RG: Assignment of human inhibitor of apoptosis protein (IAP) genes xiap, hiap-1, and hiap-2 to chromosomes Xq25 and 11q22-23 by fluorescence in situ hybridization. Genomics 1996; 37: 404-406.

23 Liston P, Roy N, Tamai $\mathrm{K}$ et al: Suppression of apoptosis in mammalian cells by NAIP and a related ramily of IAP genes. Nature 1996; 379: 349-353.

24 Frattini A, Faranda S, Bagnasco L et al: Identification of a new member (ZNF183) of the Ring finger gene family in Xq24-25. Gene 1997; 192: 291-298. 